\title{
The effect of density on aggression between a highly invasive and native fish
}

\author{
Laura K. Lopez ${ }^{1,2}$ (1) | Andrew R. Davis ${ }^{2}$ | Marian Y. L. Wong² (D)
}

${ }^{1}$ LSA Ecology and Evolutionary Biology, University of Michigan, Ann Arbor, MI, USA

${ }^{2}$ School of Biological Sciences, University of Wollongong, Wollongong, NSW, Australia

\section{Correspondence}

Laura K. Lopez, University of Michigan, Biological Sciences Building, 1105 North University, Ann Arbor, MI 48109, USA.

Email: Iklopez@umich.edu

\section{Funding information}

NSW Department of Primary Industries Saltwater and Freshwater Trust Fund, Grant/ Award Number: 91

Editor: Leonida Fusani

\begin{abstract}
Population densities of invasive species fluctuate spatially and temporally, suggesting that the intensity of their aggressive interactions with native species is similarly variable. Although inter-specific aggression is often thought to increase with population density, it is often theorized that it should be exceeded by intra-specific aggression since conspecifics share a greater degree of resource overlap. Yet, the magnitude of intra-specific aggression is seldom considered when examining aggressive interactions, particularly those between invasive and native species. Here, we manipulated the density of the invasive eastern mosquitofish, Gambusia holbrooki, and observed its aggressive interactions with juveniles of the native Australian bass, Macquaria novemaculeata in a laboratory setting. For both species, the magnitudes of intra- and inter-specific aggression were recorded. Regardless of density, the native M. novemaculeata was more aggressive towards heterospecifics than G. holbrooki was. In addition to this, $M$. novemaculeata was more aggressive to $G$. holbrooki than towards conspecifics, at both low- and high-density conditions. In contrast, G. holbrooki was similarly aggressive towards M. novemaculeata and G. holbrooki at a high density, yet at low density, displayed significantly more aggression towards conspecifics than M. novemaculeata. These findings demonstrate the importance of considering intra-specific aggression when exploring behavioural interactions between native and invasive species.
\end{abstract}

KEYWORDS

aggression, density, Gambusia holbrooki, invasive, Macquaria novemaculeata

\section{1 | INTRODUCTION}

Biological invasions can have a significant deleterious effect on global biodiversity and ecosystem functioning (Gallardo, Clavero, Sanchez, \& Vila, 2016; Holway \& Suarez, 1999; Mack et al., 2000). Often invaders engage in interference competition with native species which can include contests, territoriality and nest vandalism (Amarasekare, 2002; Case \& Gilpin, 1974; Human \& Gordon, 1996; Zhang, Andersen, Dieckmann, \& Brannstrom, 2015). The underlying commonality that unites these interactions is some form of aggression (Grether et al., 2013). Invasive species are frequently observed to display more inter-specific aggression than native species, which is often considered to be a key factor in their success in spreading to and becoming established in novel systems (Holway \& Suarez, 1999; Hudina, Hock, \& Zganec, 2014; Pintor, Sih, \& Bauer, 2008). The ultimate outcome of aggressive interactions may be the displacement of a native species as their access to food, shelter and reproductive partners becomes increasingly limited (Amarasekare, 2002).

The intensity and outcome of aggression between invasive and native species is frequently context dependent (Hudina, Zganec, \& Hock, 2015; Jackson, Ruiz-Navarro, \& Britton, 2015; Kaiser et al., 2013). The abundance of many invaders can be temporally and 
spatially heterogeneous, which in turn suggests that the intensity of their aggressive interactions with natives may be similarly variable (Latzka, Hansen, Kornis, \& Vander Zanden, 2016). Aggressive interactions have typically been thought to increase with the population density of an invader due to a higher rate of contact with native competitors as well as a reduction in resources relative to population size (Kaiser et al., 2013). However, the frequency of intra-specific interactions within an invasive population is also likely to increase with its density, which may lead to a reduction in inter-specific interactions due to altered contact rates, and the co-existence of invasive and native competitors (Britton, Cucherousset, Grey, \& Gozlan, 2011; Kornis, Carlson, Lehrer-Brey, \& Vander Zanden, 2014). Therefore, in order to predict the effects of an invader's density on native species, it is necessary to examine the relative magnitude of inter-specific and intra-specific aggression that each species may experience (Inouye, 2001).

It is often theorized that behavioural interactions between conspecifics should be stronger than those between heterospecifics, particularly at high population densities (Connell, 1983; Forrester, Evans, Steele, \& Vance, 2006; Munday, Jones, \& Caley, 2001). This is because conspecifics share a higher degree of resource overlap and may be viewed as greater rivals than heterospecifics (Connell, 1983; Forrester et al., 2006; Munday, 2004). For example, both the coral dwelling bridled goby (Coryphopterus glaucofraneum) and goldspot goby (Gnatholepis thompsoni) were reported to be at least twice as aggressive towards conspecifics than towards heterospecifics (Forrester et al., 2006). However, support for this prediction is overwhelmingly provided by studies of species in their natural ranges (Connell, 1983; Goldberg \& Barton, 1992; Mangla, Sheley, James, \& Radosevich, 2011), neglecting the possibility that the behaviour of invasive species which are by definition outside of their native ranges may be inherently different to that of native species (Hansen et al., 2013; Latzka et al., 2016). For example, Argentine ant (Linepithema humile) populations are known to display reduced intra-specific aggression between nests outside compared to within their native ranges (Tsutsui, Suarez, Holway, \& Case, 2000). The result of lowered intra- compared with inter-specific aggression may be reduced levels of population self-regulation (Pintor et al., 2008). Alternatively, invaders could be similarly aggressive to hetero- and conspecifics which may also reduce population self-regulation to a degree (Sale, 1977). However, since the relationship between intraand inter-specific aggression and density remains poorly studied, there is no current consensus as to which model invaders, or the native species they interact with, may conform to.

Here, we quantified the magnitude of inter- and intra-specific aggression between the native Australian Bass, Macquaria novemaculeata, Steindachner, 1966, and the invasive eastern mosquitofish, Gambusia holbrooki, Girard, 1859, and how both forms of aggression are mediated by $G$. holbrooki density. Since its introduction into Australia in the 1920s, G. holbrooki has spread to all states and territories (Pyke, 2008). Its aggressive behaviour, including fin-nipping, is frequently cited as a key mechanism behind its success as an invader (Carmona-Catot, Magellan, \& Garcia-Berthou, 2013; Pyke,
2008; Sutton, Zeiber, \& Fisher, 2013). Not only does the density of G. holbrooki vary spatially, but also populations of the invader are also known to experience seasonal fluctuations, with densities being highest following breeding in early autumn and lowest in spring (Barney \& Anson, 1921).

Juveniles of the native M. novemaculeata are stocked extensively throughout the East Australian drainage system to support populations no longer able to reach estuaries and breed due to habitat modification (Cameron, Baumgartner, Bucher, \& Robinson, 2012). Adult M. novemaculeata are piscivorous and have been observed to attack G. holbrooki in a captive setting (Grigaltchik, Ward, \& Seebacher, 2012), suggesting that juvenile M. novemaculeata may also attempt to consume G. holbrooki. However, interactions between juvenile M. novemaculeata and G. holbrooki have not been recorded thus far, despite there being a number of factors which suggest that recently stocked $M$. novemaculeata may be vulnerable in the presence of the invader. Since stocked juvenile $M$. novemaculeata are hatchery reared, they are potentially naïve to $G$. holbrooki and unlike wild fingerlings which have had previous experience with $G$. holbrooki and may have adapted their behaviour to avoid interactions with the invader. Therefore, although they may not necessarily receive more aggression than wild fingerlings, they may be less adept at responding to $G$. holbrooki. In addition to this, G. holbrooki will have prior residence over the newly released $M$. novemaculeata which may infer a competitive advantage to the invader (Peeke, Sippel, \& Figler, 1995). Considering these factors, it is possible that G. holbrooki could significantly impede the conservation of $M$. novemaculeata by inflicting injury and increasing the mortality rate of juvenile $M$. novemaculeata used in stocking programmes.

Overall, we expected that the strength of aggressive interactions would vary depending on the species (invasive vs. native), type of aggression (intra vs. inter) and density of animals (high vs. low). We predicted that (a) G. holbrooki, as an invasive species in this context, will be more aggressive towards heterospecifics than $M$. novemaculeata would be to heterospecifics. Following on from this, we also predicted that (b) the native $M$. novemaculeata will be more aggressive to conspecifics than heterospecifics at high density. Finally, since invasive species may display unique inter- and intra-specific interaction dynamics, that (c) G. holbrooki would will be more aggressive towards heterospecifics than conspecifics at high density.

\section{2 | METHODS}

\section{1 | Study species and acclimation}

Adult eastern mosquitofish, G. holbrooki, (all values are $\bar{x} \pm S E$ unless stated otherwise; male, mass $=0.14 \pm 0.01 \mathrm{~g}$; standard length $=20.43 \pm 0.20 \mathrm{~mm}$; female, mass $=0.14 \pm 0.01 \mathrm{~g}$; standard length $=20.01 \pm 0.27 \mathrm{~mm}$ ), were collected from freshwater ponds located at the University of Wollongong campus, NSW, Australia $\left(34^{\circ} 24^{\prime} 19^{\prime \prime} \mathrm{S} 150^{\circ} 52^{\prime} 42^{\prime \prime} \mathrm{E}\right)$ using a baited hand-held landing net. There was no significant difference in length of male and female G. holbrooki $\left(t_{98}=0.28, p=.779\right)$. While adult female G. holbrooki 


\begin{tabular}{llll} 
& $\begin{array}{l}\text { Macquaria novemaculeata } \\
\text { intra-specific }\end{array}$ & Mixed & $\begin{array}{l}\text { Gambusia holbrooki } \\
\text { intra-specific }\end{array}$ \\
\hline Low density & $1 \mathrm{Mn}$ & $1 \mathrm{Gh}^{*}$ & $1 \mathrm{Gh}^{*}$ \\
& $2 \mathrm{Mn}^{*}$ & $2 \mathrm{Mn}^{*}$ & $2 \mathrm{Gh}$ \\
High density & $4 \mathrm{Mn}$ & $4 \mathrm{Gh}^{*}$ & $4 \mathrm{Gh}^{*}$ \\
& $2 \mathrm{Mn}^{*}$ & $2 \mathrm{Mn}^{*}$ & $2 \mathrm{Gh}$
\end{tabular}

TAB LE 1 Densities of Gambusia

holbrooki (Gh) and Macquaria

novemaculeata $(\mathrm{MN})$ used in this

experiment $(n=10)$

Note: The aggression of focal fish (marked with *) was recorded. For each species, aggression from individuals in the low- and high-density mixed treatments was compared with those in the intraspecific treatments to determine whether the preference to interact with con- or heterospecific differed with density.

are typically larger than males (Pyke, 2008), fish for the present study were collected during late autumn and early winter when male and female young of the year born in spring were prevalent and fully mature females were rare (Lopez, pers. obs.). Juvenile Australian bass, $M$. novemaculeata (mass $=0.97 \pm 0.03 \mathrm{~g}$; standard length $=36.17 \pm 0.35 \mathrm{~mm}$ ) of mixed sex were obtained from a local hatchery (Aquablue Seafoods). Juvenile M. novemaculeata used in this study were similar in size to those stocked into waterways (Hutchison et al., 2006) to better assess whether G. holbrooki negatively impacts stocking of this native species. This species was not sexed as this can only be done post-mortem, which was not possible in this study. Furthermore, it is likely that sex-specific differences in aggression in M. novemaculeata have not emerged at this developmental stage (Johnsson, Sernland, \& Blixt, 2001). Both G. holbrooki and $M$. novemaculeata are generalist species which feed on zooplankton, insect larvae and insects (Pyke, 2008; Smith, Baumgartner, Suthers, \& Taylor, 2011). Piscivory has been recorded in M. novemaculeata as small as $67 \mathrm{~mm}$, yet it is not common until individuals are longer than $100 \mathrm{~mm}$ (Smith et al., 2011).

To conduct the experiment, 4 recirculating aquarium systems in temperature-controlled rooms were used at the University of Wollongong. Each system consisted of 8 aquaria $(60 \times 30 \times 30 \mathrm{~cm})$ that were inter-connected and subjected to water conditions held constant at $21^{\circ} \mathrm{C}$ and 15 ppt salinity. Each aquarium was aerated with a bubbler, lined with $2 \mathrm{~cm}$ of sand and contained 1 PVC pipe $(15 \times 6 \mathrm{~cm})$ to provide shelter. To house M. novemaculeata, 24 aquaria ( $N=130$ total fish) were established across 4 separate systems ( $N=33$ or $N=32$ fish per system). For $G$. holbrooki, 8 aquaria ( $N=140$ total fish) were used across 4 separate systems $(N=35$ fish per system). All fish remained under these conditions for the 7 days to ensure adequate acclimation. During this time, both species were maintained at a 12:12 light:dark cycle and fed an equal amount of a commercial fish pellet (New Life Spectrum Thera formula) and frozen bloodworms daily. During acclimation, intra-specific aggressive interactions were not recorded. Individuals were re-randomized when introduced from housing aquaria to observation aquaria to avoid familiarization.

\section{2 | Experimental design}

To examine inter- and intra-specific aggression in G. holbrooki and M. novemaculeata under low and high densities of $G$. holbrooki, we established 3 experimental treatments: (a) mixed, in which aquaria contained both $G$. holbrooki and $M$. novemaculeata ( $N=20$ groups), (b) $M$. novemaculeata intra-specific, in which aquaria contained only M. novemaculeata ( $N=20$ groups) and (c) G. holbrooki intraspecific where only $G$. holbrooki were present in aquaria $(N=20$ groups). Within all treatments, 2 density levels were establishedlow density (containing 3 fish in total) and high density (containing 6 fish in total; Table 1). For the mixed treatment, the number of G. holbrooki was 1 for the low-density level ( $N=10$ groups) and 4 for the high-density level ( $N=10$ groups), while the density of M. novemaculeata was held constant at 2 individuals (Table 1 ). The total number of M. novemaculeata and G. holbrooki in the intra-specific treatments was the same as the total number of both species (combined) in the corresponding low- and high-density mixed treatments (Table 1).

We used a form of response surface design developed to isolate the relative levels of intra- and inter-specific aggression (Forrester et al., 2006; Inouye, 2001). The behaviour of one focal individual in the $G$. holbrooki single-species treatment and multiple focal individuals in the other treatments was recorded. Behavioural interactions among focal individuals were not recorded in this study. Focal individuals were randomly selected. The aggression displayed by individuals to heterospecifics was compared with that directed to conspecifics in the mixed- and single-species treatments, respectively. For example, we recorded aggression displayed by the sole G. holbrooki in the low-density mixed treatment compared with that of the sole focal $G$. holbrooki towards non-focal individuals in the low-density G. holbrooki single-species treatment. These observations show how inter- and intra-specific aggression varied independently of overall fish density. This is contrasted against levels of inter- and intra-specific aggression displayed by focal G. holbrooki in the high-density mixed and G. holbrooki single-species treatments to ascertain how animal density affects the relative aggression displayed towards con- and heterospecifics. Since the goal of the experiment was to examine how the density of an invasive species affects intra- and inter-specific aggression, we solely manipulated densities of $G$. holbrooki and not $M$. novemaculeata in the mixed treatments.

Due to the time of year in which G. holbrooki were collected, fish densities in local populations were relatively low (Lopez, pers. obs.). We were unable to consistently collect enough males or females to use a single sex throughout the experiment, and the 
relative abundances of the sexes changed over the course of the experiment. For this reason, we used both sexes in mixed groups in the high-density intra-specific and mixed treatments. In the highdensity intra-specific and mixed treatments, the densities of focal male and female $G$. holbrooki varied so that replicates contained either 4 males ( $n=2$ ), 4 females ( $n=2$ ), 2 males and 2 females $(n=2), 3$ males and 1 female $(n=2)$ or 1 male and 3 females $(n=2)$. In both the low-density intra-specific and mixed treatments, the number of replicates containing male and female focal $G$. holbrooki was equal ( $n=5$ male, $n=5$ female). Wild densities $G$. holbrooki were estimated following collections made over time in the source ponds, giving an approximation of seasonal changes in density. The overall densities of individuals used in the study were based on estimates of seasonal low and high G. holbrooki densities in Wollongong water bodies relative to the aquaria size used in this study (Lopez, pers. obs.).

\section{3 | Behavioural observations}

Following an acclimation period of 2 weeks, M. novemaculeata and G. holbrooki were captured using hand nets, measured using handheld callipers, ( $\mathrm{mm}$ standard $(\mathrm{SL}) \pm 0.1 \mathrm{~mm}$ ) and weighed with an electronic balance (grams $(\mathrm{g}) \pm 0.1 \mathrm{~g}$ ). To enable the identification of individuals and to control for any effect of sex, size and reproductive status, each fish was tagged with fluorescent polymer elastomer tags (yellow, green, red, pink and orange; Northwest Industries Ltd) which was injected subcutaneously into the dorsal musculature (Malone, Forrester, \& Steele, 1999).

In the mixed and G. holbrooki intra-specific treatments, 1 G. holbrooki (low density) or $4 \mathrm{G}$. holbrooki (high density) were introduced into a test aquarium $(60 \times 30 \times 30 \mathrm{~cm}) 24 \mathrm{hr}$ prior to the addition of 2 focal G. holbrooki or M. novemaculeata (Table 1). In the M. novemaculeata intra-specific treatment, $1 \mathrm{M}$. novemaculeata (low-density level) or $4 \mathrm{M}$. novemaculeata (high-density level) were introduced into a test aquarium $24 \mathrm{hr}$ prior to the addition of 2 focal M. novemaculeata (Table 1). This order of residency was intended to simulate the temporal occurrence of species in the event of fish stocking whereby G. holbrooki is present prior to the introduction of $M$. novemaculeata.

Observations commenced after a 30-min acclimation period followed by a 5-min habituation to the presence of the observer. Only one person (LKL) observed the fish to avoid potential issues with observer bias. Each focal individual was observed for 10 min during which time the number of aggressive (approaches, chases and nips) behavioural interactions between other individuals was recorded (Flood \& Wong, 2017; Matthews \& Wong, 2015; O'Mara \& Wong, 2015). To account for diurnal variation in behaviour, the same fish were observed once in the morning (0900-1200) and once in the afternoon (1300-1600). As no significant variation in the frequency of aggressive behaviours between the $\mathrm{AM}$ and $\mathrm{PM}$ observation periods were found for neither M. novemaculeata (GLMM, Time; $F_{1,152}=0.68$, $p=.41$ ) nor $G$. holbrooki (Time; $F_{1,169}=0.01, p=.99$ ), the number of discrete aggressive behaviours performed by each individual in the
AM and PM observation periods was summed, giving data for 20 min of observation time for each focal individual.

\subsection{Statistical analysis}

A number of $G$. holbrooki died following interactions with $M$. novemaculeata in the low $(n=1)$ - and high $(n=6)$-density mixed treatments (out of a total $50 \mathrm{G}$. holbrooki in mixed conditions), and so behavioural data collected from these individuals were excluded from all subsequent analyses.

All statistical analyses were conducted in RSTUDıO version 3.5.1 (R Core Team, 2016) using the MASS package. We used generalized linear mixed models (GLMMs) with negative binomial distributions which accounted for overdispersion in the count data (Dellinger, Zhang, Bell, \& Hellmann, 2018; Zuur, leno, Walker, Savaliev, \& Smith, 2009).

The first model compared whether M. novemaculeata or G. holbrooki were more aggressive to heterospecifics in the low- and highdensity mixed conditions of the experiment. It included density (binomial: high or low), species (binomial: G. holbrooki or M. novemaculeata) as fixed effects and an interaction between density and species. We also included body length (continuous) as a covariate in the model to control for variation due to size and tank ID as a random effect to control for the non-independence of aggression and variation in G. holbrooki sex ratios. Fish ID was not included in any model since we did not use a repeated measures approach.

To compare whether M. novemaculeata and G. holbrooki showed different levels of aggression to con- or heterospecifics at low- and high-density conditions, we ran two separate models, one for each species. Both models included density and treatment (binomial: mixed or intra-specific) and the interaction between these fixed effects. Once again body length was included as a covariate and tank ID as a random effect. For the model, comparing the levels of aggression displayed by G. holbrooki, sex (binomial: male or female), was also included as a factor to control for any variation in aggression arising from sex. Non-significant interaction terms were removed from all models, and since sex was not a significant factor in any model, it was removed from the final analysis. Following application of the Bonferroni correction, the alpha value was adjusted to 0.016 for the all models. Post hoc analyses were conducted using the package Ismeans.

\section{5 | Ethical note}

At the conclusion of the experiment, G. holbrooki were euthanized using clove oil since it is illegal to release an invasive species under NSW law. Macquaria novemaculeata were used in another experiment covered by a separate protocol. Animal collection and husbandry, collection of observational data and euthanasia protocols were approved by the University of Wollongong Animal Ethics Committee (protocol AE14/07) and adhered to the Scientific Collection guidelines (permit No. P13/0011-1.3) of the NSW Department of Primary Industries. 


\section{3 | RESULTS}

Regardless of density level, M. novemaculeata was more aggressive towards heterospecifics than G. holbrooki was (Figure 1, Table 2). At low density, M. novemaculeata were approximately twice as aggressive towards heterospecifics than $G$. holbrooki was, while at high density, M. novemaculeata were approximately 4 times more aggressive towards heterospecifics than G. holbrooki. Only M. novemaculeata was more aggressive towards heterospecifics in high- than low-density conditions as there was no significant difference in aggression from $G$. holbrooki in the high- and low-density conditions (Figure 1, Table 2).

At both density levels, M. novemaculeata were more aggressive towards G. holbrooki than conspecifics. This difference was magnified at high compared with low G. holbrooki densities, yet there was no significant effect of density alone and no interaction between density and treatment (Figure 2a, Table 3a). In contrast to M. novemaculeata, aggression from $G$. holbrooki to both M. novemaculeata and conspecifics at high density was minimal. At low density, however, G. holbrooki were significantly more aggressive to conspecifics than M. novemaculeata (Figure 2b, Table 3b).

\section{4 | DISCUSSION}

The relationship between the density of an invader and the intensity of aggressive interactions between invasive and native species differs greatly between study species and ecosystems (Yokomizo, Possingham, Thomas, \& Buckley, 2009). Contrary to our predictions, the native species, $M$. novemaculeata, was more aggressive towards heterospecifics than was the invasive species, G. holbrooki. In addition to this, M. novemaculeata displayed more aggression to $G$. holbrooki than other M. novemaculeata. Also, unexpectedly, G. holbrooki was equally aggressive to $M$. novemaculeata and other $G$. holbrooki

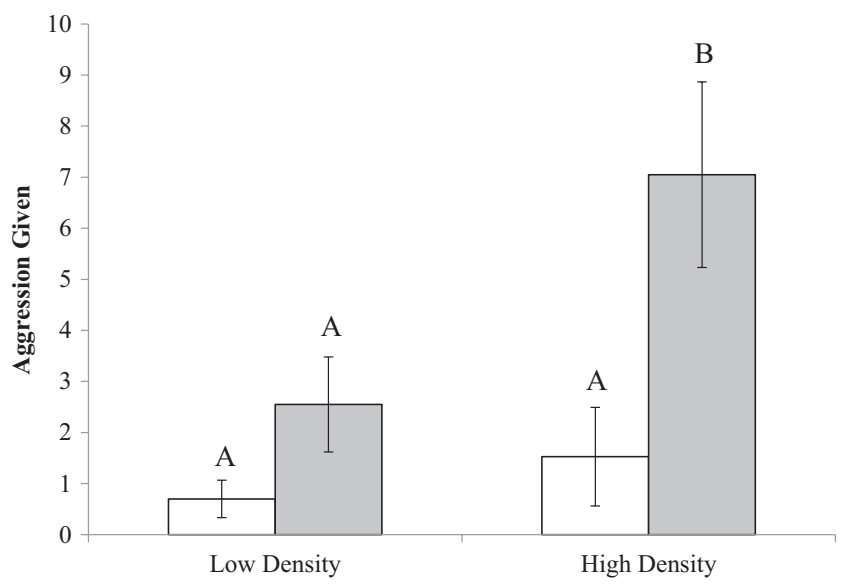

FIGURE 1 Mean $( \pm S E)$ inter-specific aggression from Gambusia holbrooki (open bars) and Macquaria novemaculeata (closed bars) at low and high $G$. holbrooki densities towards focal heterospecifics, $n=10$ at high density, although it was markedly more aggressive towards conspecifics at low density. These results demonstrate that the relative levels of intra- and inter-specific aggression, specifically from a native species towards an invader, and from a invader towards conspecifics, can shift unexpectedly with an invader's density.

Numerous invasive species have been reported to be more aggressive than the natives with which they interact (Carmona-Catot et al., 2013; Howe, Howe, Lim, \& Burchett, 1997; Rincon, Correas, Morcillo, Risueno, \& Lobon-Cervia, 2002). Despite this, and in contrast to our first prediction, the native $M$. novemaculeata displayed more aggression to heterospecifics than did G. holbrooki at high density. This finding may be related to size differences between native and invasive species in the current study. Where asymmetric

TAB LE 2 Results of a generalized linear mixed model (negative binomial distribution) comparing the effects of Gambusia holbrooki density on inter-specific aggression from Macquaria novemaculeata and G. holbrooki

\begin{tabular}{lll} 
& $Z_{82}$ & $p$ \\
\hline Density & -2.726 & .006 \\
Species & -2.722 & .006 \\
Density $\times$ species & 1.806 & .071 \\
Length & 0.026 & .979 \\
\hline
\end{tabular}

Note: Non-significant interactions were backward stepwise removed $(p<.016)$.

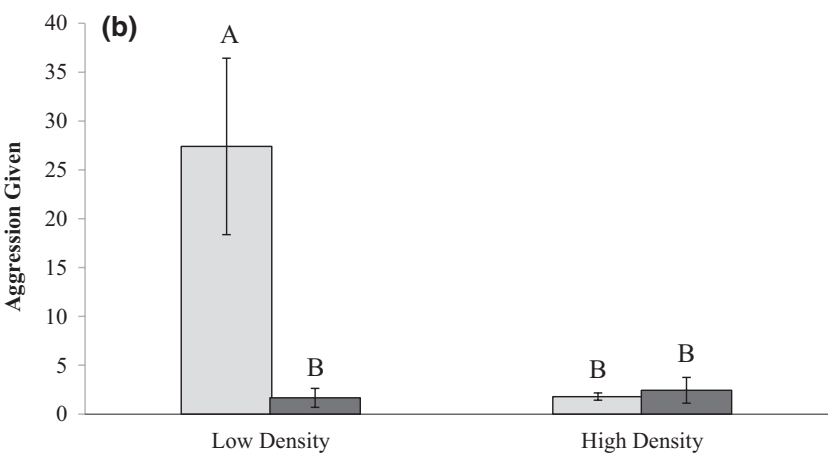

FIGURE 2 Mean $( \pm S E)$ aggression from (a) Macquaria novemaculeata and (b) Gambusia holbrooki to non-focal conspecifics (light grey bars) and heterospecifics (dark grey bars) at low and high G. holbrooki densities, $n=10$ 
TAB LE 3 Result of generalized linear mixed models (negative binomial distribution) testing the effects of Gambusia holbrooki density and treatment on (a) Macquaria novemaculeata and (b) G. holbrooki aggression

$\begin{array}{lcc} & Z_{79} & p \\ \text { (a) Macquaria novemaculeata } & & .071 \\ \text { Density } & -1.806 & <.0001 \\ \text { Treatment } & 5.558 & .059 \\ \text { Density } \times \text { treatment } & -1.890 & .041 \\ \text { Length } & 2.045 & p\end{array}$

(b) Gambusia holbrooki

\begin{tabular}{lll} 
Density & 4.264 & $<.0001$ \\
Treatment & -0.776 & .438 \\
\hline Density $\times$ treatment & -2.437 & .015 \\
Length & 0.529 & .597 \\
Sex & 1.258 & .208 \\
\hline
\end{tabular}

Note: Non-significant interactions were backward stepwise removed $(p<.016)$.

aggression is observed, the larger species is often more aggressive (Little, Draud, \& Itzkowitz, 2013; Moretz, 2003), and in the present study, M. novemaculeata were on average 1.67 times longer than G. holbrooki. Similarly, Garcia and Arroyo (2002) reported that the hen harrier raptor (Circus cyaneus) was larger and more aggressive towards heterospecifics than the Montagu harrier (Circus pygargus). It is possible that since M. novemaculeata were both larger in size and also juveniles, they had a greater energetic requirement (Bystrom, Andersson, Kiessling, \& Eriksson, 2006; Bystrom \& García-Berthou, 1999; Ohlberger, Mehner, Staaks, \& Holker, 2012) and therefore may have placed a higher value on food when $G$. holbrooki density was high and hence exhibited higher rates of aggression towards the invader. In addition to this, larger, more mature $G$. holbrooki than those used in this study may have been more prone to aggression towards M. novemaculeata.

To understand the effect that density has on inter-specific aggression, it is necessary to consider the strength of intra-specific interactions (Connell, 1983; Forrester et al., 2006; Inouye, 2001). In opposition to our second prediction, $M$. novemaculeata were more aggressive to $G$. holbrooki than M. novemaculeata at either low or high density. This result contradicts expectations that intra-specific aggression should exceed that directed to heterospecifics. It is important to note that the majority of studies which support this concept have solely observed interactions between species in their native ranges and thus do not account for invasive-native species dynamics. Indeed, inter-specific aggression has been observed to be greater or equal to intra-specific aggression for some native species competing with invaders (Tsutsui et al., 2000; Warnock \& Rasmussen, 2013). For example, Warnock and Rasmussen (2013) reported that the autochthonous bull trout (Salvelinus confluentus) diverted more aggression towards a high density of the non-native brook trout (Salvelinus fontinalis) than conspecifics. Our results demonstrate that there is a need to further explore the relative strengths of inter- and intra-specific aggressive interactions between invasive and native species.

Considering that a disparity in body size may have mediated inter-specific aggression between $M$. novemaculeata and $G$. holbrooki, it is also necessary to consider the role of size in determining the relative magnitude of intra- and inter-specific competition for $M$. novemaculeata. If an increase in resource value at high competitor densities led to increased inter-specific aggression in this study, a comparable or greater increase in intra-specific aggression may also be expected. However, aggression is a costly behaviour and the risk of injury as a result of direct interactions typically increases for an individual with the relative body size of their competitor (Garcia \& Arroyo, 2002; Herrel et al., 2009; Huntingford, Metcalfe, Thorpe, Graham, \& Adams, 1990). Future studies could also benefit from exploring interactions between $M$. novemaculeata of different age classes to determine whether there are other factors aside from body size, such as social dynamics and disputes over resources, which influence intra-specific aggression in this species.

It has been hypothesized that one of the behavioural differences between species in native and non-native ranges is lower levels of intra- compared with inter-specific aggression at high densities (Pintor, Sih, \& Kerby, 2009; Tsutsui et al., 2000). In contrast to our fourth prediction, however, inter- and intra-specific aggression from G. holbrooki was equal in high-density conditions. This may suggest that under a high density of G. holbrooki, con- and heterospecifics represented the same level of threat to individuals, as per the lottery model (Sale, 1977). This result contradicts previous studies which report stronger inter- than intraspecific aggression in invaders (Tsutsui et al., 2000; Warnock \& Rasmussen, 2013). However, there is also evidence that invaders can be equally aggressive to con- and heterospecifics (Kalinoski, 1975) or aggressive more so towards con- than heterospecifics (Sutton et al., 2013). Considering that M. novemaculeata may have 
been more aggressive towards heterospecifics than was G. holbrooki because they were larger, it follows that $G$. holbrooki may have limited its aggressive behaviour towards M. novemaculeata in order to reduce the risk of injury or predation.

It is important to note that aside from differences in body size potentially mediating aggression, an additional explanation of the results presented here may be that $M$. novemaculeata was driven to consume $G$. holbrooki (making the motivation predation rather than simply aggression over territory). A small number of $G$. holbrooki were killed following aggressive interactions with $M$. novemaculeata, and in a number of these cases, $M$. novemaculeata attempted to consume the invader, yet were unsuccessful due to limited gape size. It is interesting to note, however, that there was no apparent anti-predator response from G. holbrooki following exposure to $M$. novemaculeata. Neither species utilized shelters provided in the study, and the levels of aggression displayed by G. holbrooki to $M$. novemaculeata and conspecifics were all similar except for the high levels of intra-specific aggression in the low-density treatment. However, we cannot dismiss the possibility that there are multiple body size-mediated negative interactions (predation and aggression) occurring between these species. In the future, it would therefore be beneficial to track the outcome of aggressive interactions between these species over a range of size classes. This would help to determine at what stage following stocking $M$. novemaculeata are likely to receive most aggression from G. holbrooki and whether the release of older M. novemaculeata fingerlings would assist in controlling this invader in waterways. Furthermore, it could reveal whether $G$. holbrooki are a food source for adult $M$. novemaculeata in the wild, and so may provide some benefit for the native.

In conclusion, the present study demonstrates that value of measuring the relative magnitudes of inter- and intra-specific interactions when examining aggression between invasive and native species. Taken together, our findings suggest that $M$. novemaculeata may be more aggressive than $\mathrm{G}$. holbrooki at high densities of the invader and displays more aggression when exposed to the invader than conspecifics. Therefore, where $M$. novemaculeata juveniles are released into waterbodies containing a high density of $G$. holbrooki, the invader may be more likely to experience the negative effects of these aggressive interactions, including slower growth, higher injury and mortality and increased vulnerability to predation may be observed (Zhang et al., 2015).

\section{ACKNOWLEDGEMENTS}

The authors thank Paul Gordon and Daniel Swadling for their assistance. This project was supported by an NSW Department of Primary Industries Saltwater and Freshwater Trust Fund awarded to L.K. Lopez (No. 91). M.Y.L. Wong and A.R. Davis received funding from the Centre of Sustainable Ecosystem Solutions, School of Biological Sciences at the University of Wollongong, NSW. L.K. Lopez received the support of an Australian Government Research Training Program Scholarship.

\section{CONFLICT OF INTEREST}

None.

\section{DATA AVAILABILITY STATEMENT}

The data sets pertaining to the present study can be found in the Appendix S1.

\section{ORCID}

Laura K. Lopez (iD https://orcid.org/0000-0003-4818-1544

Marian Y. L. Wong (iD https://orcid.org/0000-0001-6393-6453

\section{REFERENCES}

Amarasekare, P. (2002). Interference competition and species coexistence. Proceedings of the Royal Society of London. Series B: Biological Sciences, 269(1509), 2541-2550. https://doi.org/10.1098/ rspb.2002.2181

Barney, R. L., \& Anson, B. J. (1921). The seasonal abundance of the mosquitodestroying top-minnow, Gambusia affinis, especially in relation to fecundity. The Anatomical Record., 22(5), 317-335.

Britton, J. R., Cucherousset, J., Grey, J., \& Gozlan, R. E. (2011). Determining the strength of exploitative competition from an introduced fish: Roles of density, biomass and body size. Ecology of Freshwater Fish, 20(1), 74-79. https://doi. org/10.1111/j.1600-0633.2010.00460.x

Bystrom, P., Andersson, J., Kiessling, A., \& Eriksson, L. O. (2006). Size and temperature dependent foraging capacities and metabolism: Consequences for winter starvation mortality in fish. Oikos, 115(1), 43-52. https://doi.org/10.1111/j.2006.0030-1299.15014.x

Bystrom, P., \& García-Berthou, E. (1999). Density dependent growth and size specific competitive interactions in young fish. Oikos, 86(2), 217-232. https://doi.org/10.2307/3546440

Cameron, L. M., Baumgartner, L. J., Bucher, D. J., \& Robinson, W. (2012). Critical Thermal Minima of age- 0 Australian bass, Macquaria novemaculeata, fingerlings: Implications for stocking programmes. Fisheries Management and Ecology, 19(4), 344-351. https://doi. org/10.1111/j.1365-2400.2012.00850.x

Carmona-Catot, G., Magellan, K., \& Garcia-Berthou, E. (2013). Temperature-specific competition between invasive mosquitofish and an endangered cyprinodontid fish. PLoS ONE, 8(1), e54734. https ://doi.org/10.1371/journal.pone.0054734

Case, T. J., \& Gilpin, M. E. (1974). Interference competition and niche theory. Proceedings of the National Academy of Sciences of the United States of America, 71(8), 3073-3077. https://doi.org/10.1073/ pnas.71.8.3073

Connell, J. H. (1983). On the prevalence and relative importance of interspecific competition - Evidence from field experiments. American Naturalist, 122(5), 661-696. https://doi.org/10.1086/284165

Dellinger, M., Zhang, W. R., Bell, A. M., \& Hellmann, J. K. (2018). Do male sticklebacks use visual and/or olfactory cues to assess a potential mate's history with predation risk? Animal Behaviour, 145, 151-159. https://doi.org/10.1016/j.anbehav.2018.09.015

Flood, C. E., \& Wong, M. Y. L. (2017). Social stability in times of change: Effects of group fusion and water depth on sociality in a globally invasive fish. Animal Behaviour, 129, 71-79. https://doi.org/10.1016/j. anbehav.2017.05.003

Forrester, G. E., Evans, B., Steele, M. A., \& Vance, R. R. (2006). Assessing the magnitude of intra- and interspecific competition in two coral 
reef fishes. Oecologia, 148(4), 632-640. https://doi.org/10.1007/ s00442-006-0397-0

Gallardo, B., Clavero, M., Sanchez, M. I., \& Vila, M. (2016). Global ecological impacts of invasive species in aquatic ecosystems. Global Change Biology, 22(1), 151-163. https://doi.org/10.1111/gcb.13004

Garcia, J. T., \& Arroyo, B. E. (2002). Intra- and interspecific agonistic behaviour in sympatric harriers during the breeding season. Animal Behaviour, 64(1), 77-84. https://doi.org/10.1006/anbe.2002.3035

Goldberg, D. E., \& Barton, A. M. (1992). Patterns and consequences of interspecific competition in natural communities - A review of field experiments with plants. American Naturalist, 139(4), 771-801. https ://doi.org/10.1086/285357

Grether, G. F., Anderson, C. N., Drury, J. P., Kirschel, A. N. G., Losin, N., Okamoto, K., \& Peiman, K. S. (2013). The evolutionary consequences of interspecific aggression. In T. A. Mousseau, \& C. W. Fox (Eds.), Year in evolutionary biology. NY, USA: Annals of the New York Academy of Sciences. (Vol. 1289, pp. 48-68).

Grigaltchik, V. S., Ward, A. J. W., \& Seebacher, F. (2012). Thermal acclimation of interactions: Differential responses to temperature change alter predator-prey relationship. Proceedings of the Royal Society B: Biological Sciences, 279(1744), 4058-4064. https://doi.org/10.1098/ rspb.2012.1277

Hansen, G. J. A., Vander Zanden, M. J., Blum, M. J., Clayton, M. K., Hain, E. F., Hauxwell, J., ... Sharma, S. (2013). Commonly rare and rarely common: Comparing population abundance of invasive and native aquatic species. PLoS ONE, 8(10), e77415. https://doi.org/10.1371/ journal.pone.0077415

Herrel, A., Andrade, D. V., de Carvalho, J. E., Brito, A., Abe, A., \& Navas, C. (2009). Aggressive behavior and performance in the Tegu lizard Tupinambis merianae. Physiological and Biochemical Zoology, 82(6), 680-685. https://doi.org/10.1086/605935

Holway, D. A., \& Suarez, A. V. (1999). Animal behavior: An essential component of invasion biology. Trends in Ecology and Evolution, 14(8), 328-330. https://doi.org/10.1016/S0169-5347(99)01636-5

Howe, E., Howe, C., Lim, R., \& Burchett, M. (1997). Impact of the introduced poeciliid Gambusia holbrooki (Girard, 1859) on the growth and reproduction of Pseudomugil signifer (Kner, 1865) in Australia. Marine and Freshwater Research, 48(5), 425-433. https://doi.org/10.1071/ mf96114

Hudina, S., Hock, K., \& Zganec, K. (2014). The role of aggression in range expansion and biological invasions. Current Zoology, 60(3), 401-409. https://doi.org/10.1093/czoolo/60.3.401

Hudina, S., Zganec, K., \& Hock, K. (2015). Differences in aggressive behaviour along the expanding range of an invasive crayfish: An important component of invasion dynamics. Biological Invasions, 17(11), 3101-3112. https://doi.org/10.1007/s10530-015-0936-x

Human, K. G., \& Gordon, D. M. (1996). Exploitation and interference competition between the invasive Argentine ant, Linepithema humile, and native ant species. Oecologia, 105(3), 405-412. https://doi. org/10.1007/bf00328744

Huntingford, F. A., Metcalfe, N. B., Thorpe, J. E., Graham, W. D., \& Adams, C. E. (1990). Social-dominance and body size in Atlantic salmon parr, Salmo salar L. Journal of Fish Biology, 36(6), 877-881. https://doi. org/10.1111/j.1095-8649.1990.tb05635.x

Hutchison, M., Gallagher, T., Chilcott, K., Simpson, R., Aland, G., \& Sellin, M. (2006). Impoundment stocking strategies for Australian native fishes in eastern and northern Australia: With an assessment of the value of scales as tags for stocked barramundi. Queensland, Australia: Queensland Government.

Inouye, B. D. (2001). Response surface experimental designs for investigating interspecific competition. Ecology, 82(10), 2696-2706. https:// doi.org/10.1890/0012-9658(2001)082[2696:rsedfi]2.0.co;2

Jackson, M. C., Ruiz-Navarro, A., \& Britton, J. R. (2015). Population density modifies the ecological impacts of invasive species. Oikos, 124(7), 880-887. https://doi.org/10.1111/oik.01661
Johnsson, J. I., Sernland, E., \& Blixt, M. (2001). Sex-specific aggression and antipredator behaviour in young brown trout. Ethology, 107(7), 587-599. https://doi.org/10.1046/j.1439-0310.2001.00682.x

Kaiser, H., Orford, R., Thornycroft, R., Naylor, M., Field, R., Sheppard, J., \& Magellan, K. (2013). The effects of competitor density on aggressive behaviour and resource defence in a Poeciliid fish. Journal of Applied Ichthyology, 29(6), 1264-1268. https://doi.org/10.1111/ jai.12293

Kalinoski, R. (1975). Intraspecific and interspecific aggression in house finches and house sparrows. Condor, 77(4), 375-384. https://doi. org/10.2307/1366086

Kornis, M. S., Carlson, J., Lehrer-Brey, G., \& Vander Zanden, M. J. (2014). Experimental evidence that ecological effects of an invasive fish are reduced at high densities. Oecologia, 175(1), 325-334. https://doi. org/10.1007/s00442-014-2899-5

Latzka, A. W., Hansen, G. J. A., Kornis, M., \& Vander Zanden, M. J. (2016). Spatial heterogeneity in invasive species impacts at the landscape scale. Ecosphere, 7(3), e01311. https://doi.org/10.1002/ecs2.1311

Little, K., Draud, M., \& Itzkowitz, M. (2013). Interspecific aggression in two highly similar Stegastes damselfish. Ethology Ecology and Evolution, 25(3), 227-242. https://doi.org/10.1080/03949370.2012.745451

Mack, R. N., Simberloff, D., Lonsdale, W. M., Evans, H., Clout, M., \& Bazzaz, F. A. (2000). Biotic invasions: Causes, epidemiology, global consequences, and control. Ecological Applications, 10(3), 689710. https://doi.org/10.1890/1051-0761(2000)010[0689:Biceg c]2.0.Co;2

Malone, J. C., Forrester, G. E., \& Steele, M. A. (1999). Effects of subcutaneous microtags on the growth, survival, and vulnerability to predation of small reef fishes. Journal of Experimental Marine Biology and Ecology, 237(2), 243-253. https://doi.org/10.1016/ s0022-0981(99)00003-9

Mangla, S., Sheley, R. L., James, J. J., \& Radosevich, S. R. (2011). Intra and interspecific competition among invasive and native species during early stages of plant growth. Plant Ecology, 212(4), 531-542. https:// doi.org/10.1007/s11258-011-9909-z

Matthews, S. A., \& Wong, M. Y. L. (2015). Temperature-dependent resolution of conflict over rank within a size-based dominance hierarchy. Behavioral Ecology, 26(3), 947-958. https://doi.org/10.1093/beheco/ arv042

Moretz, J. A. (2003). Aggression and RHP in the northern swordtail fish, Xiphophorus cortezi: The relationship between size and contest dynamics in male-male competition. Ethology, 109(12), 995-1008. https ://doi.org/10.1046/j.0179-1613.2003.00938.x

Munday, P. L. (2004). Competitive coexistence of coral-dwelling fishes: The lottery hypothesis revisited. Ecology, 85(3), 623-628. https://doi. org/10.1890/03-3100

Munday, P. L., Jones, G. P., \& Caley, M. J. (2001). Interspecific competition and coexistence in a guild of coral-dwelling fishes. Ecology, 82(8), 2177-2189. https://doi.org/10.1890/0012-9658(2001)082[2177:icacia]2.0.co;2

Ohlberger, J., Mehner, T., Staaks, G., \& Holker, F. (2012). Intraspecific temperature dependence of the scaling of metabolic rate with body mass in fishes and its ecological implications. Oikos, 121(2), 245-251. https://doi.org/10.1111/j.1600-0706.2011.19882.x

O'Mara, K. M., \& Wong, M. Y. L. (2015). Body size mediated effects of multiple abiotic stressors on the growth and social behaviour of an estuarine fish, Australian Bass (Macquaria novemaculeata). Environmental Biology of Fishes, 99(1), 95-104. https://doi. org/10.1007/s10641-015-0458-5

Peeke, H. V. S., Sippel, J., \& Figler, M. H. (1995). Prior residence effects in shelter defense in adult signal crayfish (Pacifastacus leniusculus (Dana)) - Results in same - sex and mixed- sex dyads. Crustaceana, 68, 873-881.

Pintor, L. M., Sih, A., \& Bauer, M. L. (2008). Differences in aggression, activity and boldness between native and introduced populations 
of an invasive crayfish. Oikos, 117(11), 1629-1636. https://doi. org/10.1111/j.1600-0706.2008.16578.x

Pintor, L. M., Sih, A., \& Kerby, J. L. (2009). Behavioral correlations provide a mechanism for explaining high invader densities and increased impacts on native prey. Ecology, 90(3), 581-587. https://doi. org/10.1890/08-0552.1

Pyke, G. H. (2008). Plague minnow or mosquito fish? a review of the biology and impacts of introduced Gambusia species. Annual Review of Ecology Evolution and Systematics, 39, 171-191. https://doi. org/10.1146/annurev.ecolsys.39.110707.173451

R Core Team (2016). R: A Language and Environment for Statistical Computing. Vienna, Austria: R Foundation for Statistical Computing.

Rincon, P. A., Correas, A. M., Morcillo, F., Risueno, P., \& Lobon-Cervia, J. (2002). Interaction between the introduced eastern mosquitofish and two autochthonous Spanish toothcarps. Journal of Fish Biology, 61(6), 1560-1585. https://doi.org/10.1006/jfbi.2002.2175

Sale, P. F. (1977). Maintenance of high diversity in coral-reef fish communities. American Naturalist, 111(978), 337-359. https://doi. org/10.1086/283164

Smith, J. A., Baumgartner, L. J., Suthers, I. M., \& Taylor, M. D. (2011). Generalist niche, specialist strategy: The diet of an Australian percichthyid. Journal of Fish Biology, 78(4), 1183-1199. https://doi. org/10.1111/j.1095-8649.2011.02926.x

Sutton, T. M., Zeiber, R. A., \& Fisher, B. E. (2013). Agonistic behavioral interactions between introduced western mosquitofish and native topminnows. Journal of Freshwater Ecology, 28(1), 1-16. https://doi. org/10.1080/02705060.2012.688492

Tsutsui, N. D., Suarez, A. V., Holway, D. A., \& Case, T. J. (2000). Reduced genetic variation and the success of an invasive species. Proceedings of the National Academy of Sciences of the United States of America, 97(11), 5948-5953. https://doi.org/10.1073/pnas.100110397

Warnock, W. G., \& Rasmussen, J. B. (2013). Assessing the effects of fish density, habitat complexity, and current velocity on interference competition between bull trout (Salvelinus confluentus) and brook trout (Salvelinus fontinalis) in an artificial stream. Canadian Journal of Zoology, 91(9), 619-625. https://doi.org/10.1139/cjz-2013-0044

Yokomizo, H., Possingham, H. P., Thomas, M. B., \& Buckley, Y. M. (2009). Managing the impact of invasive species: The value of knowing the density-impact curve. Ecological Applications, 19(2), 376-386. https ://doi.org/10.1890/08-0442.1

Zhang, L., Andersen, K. H., Dieckmann, U., \& Brannstrom, A. (2015). Four types of interference competition and their impacts on the ecology and evolution of size-structured populations and communities. Journal of Theoretical Biology, 380, 280-290. https://doi. org/10.1016/j.jtbi.2015.05.023

Zuur, A. F., leno, E. N., Walker, N. J., Savaliev, A. A., \& Smith, G. M. (2009). Mixed effects models and extentions in ecology with R statistics for biology and health. New York, NY: Springer.

\section{SUPPORTING INFORMATION}

Additional supporting information may be found online in the Supporting Information section at the end of the article.

How to cite this article: Lopez LK, Davis AR, Wong MYL. The effect of density on aggression between a highly invasive and native fish. Ethology. 2019;125:876-884. https://doi. org/10.1111/eth.12941 